\title{
TRIAL EXAMINATION OF ECO BENEVOLENT, VITALITY SPARING AND MINIMAL EFFORT PROTECTED MATERIAL BOARDS FROM REUSED PAPER SQUANDER
}

\author{
Mrs. Preethi. R, \\ Assistant Professor, \\ Sri Krishna College of Technology \\ Coimbatore, Tamil Nadu, India \\ Mr. Balamurali. K, Ms. Dona Renjith \\ Post Graduate Students \\ Sri Krishna College of Technology \\ Coimbatore, Tamil Nadu, India
}

\begin{abstract}
This work aims at developing an insulated roofing unit with recycled paper waste sustainable development. Insulated roofing units with natural cooling system which reduces the usage of air conditioning system in buildings which regulates the Human Health. To assess the probability of achieving a set of economic goals through low investment and production cost of this technology - Economic Growth. And to perform a product development with energy saving concept and to maintain the ground water levelEnvironmental conservation. In the global trend, global warming is one of the significant problem in existing environment. The Ideal way to insulate any home or industrial premises and give higher thermal resistance is to have it insulated through particular roof insulation material. It gives us multiple benefits like health, natural cooling at less cost, increase in groundwater level. It also saves money because every bit of loss in temperature can result into higher energy consumption and higher expense. This type of alternative roofing system can be implemented in power generating areas like Thermal, Nuclear and Atomic Power plants which produce high Temperature for the generation of Energy. Tests such as Compressive Strength Test, Weight, Density, and Fire Resistance Test has conducted to study the behavior of Paper Crete.
\end{abstract}

Keywords: Insulated roof, sustainable development,
Environmental conservation, Ferro paper Crete.

\section{INTRODUCTION}

Vitality is used in two structures, they incorporate Direct and Indirect sources. Direct source incorporates Heat from sun, water from downpour, air from trees, and so forth. Aberrant source incorporate wood from trees, Paper from trees, and so on.., environmental change is one of the significant worry in the present decade, when contrasting with past decade. At present, thinks about demonstrates that earths inward center gets hotten when contrasted with past decades, because of this the ground water in the earth gets vaporized and causes water shortage. Water shortage is made because of earth's temperature as well as due to synthetic developments, heat emanated from sun. Cutting the trees and developing the structure causes the avoidance of infiltration of downpour water into the ground. For the most part, solid produce parcel of co2 and warmth, this is because of warmth of hydration of bond particles in the solid. Despite the fact that we have numerous new advancements, the material procedure to oppose the warmth radiation is still stays to be costlier than traditional sort of material frameworks. To diminish the warmth radiations in structure voided chunks can be utilized. Voids in the chunk empowers the air to assimilate the warmth which is consumed by the section because of radiation from sun. The re-utilization of squanders is significant 
from various perspectives: It spares and support the normal assets which are not renewed; it diminishes the contamination of the earth and it additionally spares and reuse vitality underway procedure (Hassani, 2005).

Halfway substitution of bond by Waste paper. The bond has been supplanted by waste paper ooze as needs be in the scope of $5 \%$ to $20 \%$ by weight Paper slop carries on like bond on account of silica and magnesium properties which improve the setting of the solid (Srinivasan 2010). Mechanical properties of Paper Crete containing Newspaper Waste. (H. Yun, H. Jung and C. Choi, 2011), assessed the central mechanical properties, for example, compressive and part elasticity of paper Crete containing waste papers as a fractional substitution of Portland bond. What's more, they additionally examinations the pressure strain connection of paper Crete to assess the malleable conduct of paper Crete. They utilized Newspaper for their analysis among heaps of waste papers. Paper primarily comprises of cellulose fiber and inorganic materials so it utilized fastener by supplanting with concrete since it was normal that cellulose fiber of paper join well with bond glue well (Suganya, 2012) had completed an examination on "Light weight blocks made up of waste paper". Subsequent to completing the examination, she detailed that Paper Crete blocks are moderately light weight, and increasingly adaptable. Paper Crete blocks are possibly a perfect material for seismic tremor inclined territories. Paper Crete blocks can be utilized in assembly rooms. Since, the waste materials are utilized; it will lessen the landfills and contamination.

\section{METHODOLOGY}

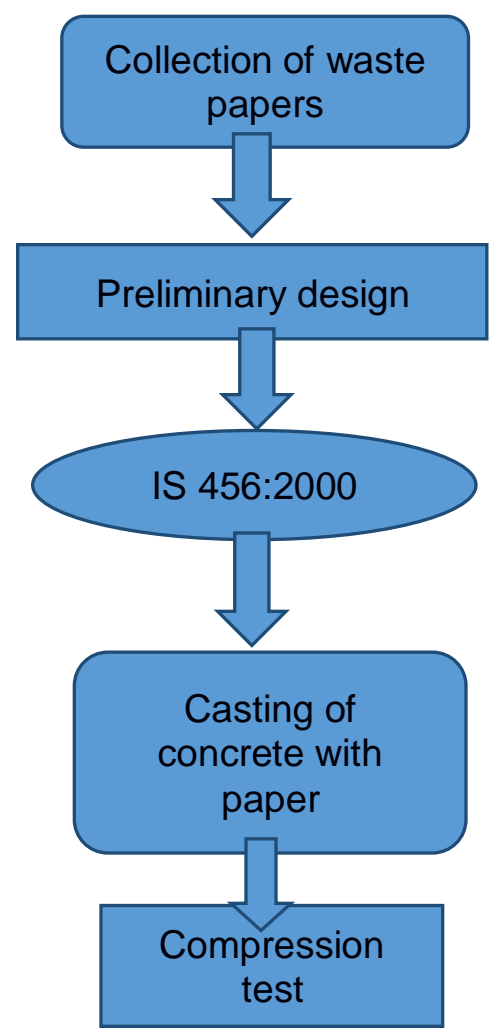

\section{MATERIALS USED AND THEIR PROPERTIES}

Bond - Ordinary Portland Cement (43 Grade) with 29 percent typical consistency adjusting to IS: 8112-1989 was utilized. The particular gravity and fineness modulus of bond are 3.15.Fine Aggregate-The properties of sand by leading tests concurring with IS 2386 (section 1) - 1963.Coarse Aggregate - Crushed stone coarse total complying with IS 383 - 1987 was utilized. The estimations of free and compacted mass thickness estimations of coarse totals were 1600 and $1781 \mathrm{Kg} / \mathrm{m} 3$. Water-Water is a significant element of concrete as it effectively takes an interest in compound responses with bond. Clean consumable water complying with IS 456 - 2000 was utilized for the readiness of solid blend.

\section{PROJECT BACKGROUND}

As of late, the greater part of the nations have created numerous activities going for the diminishing of vitality utilization and improving carbon execution of the developed structures. 


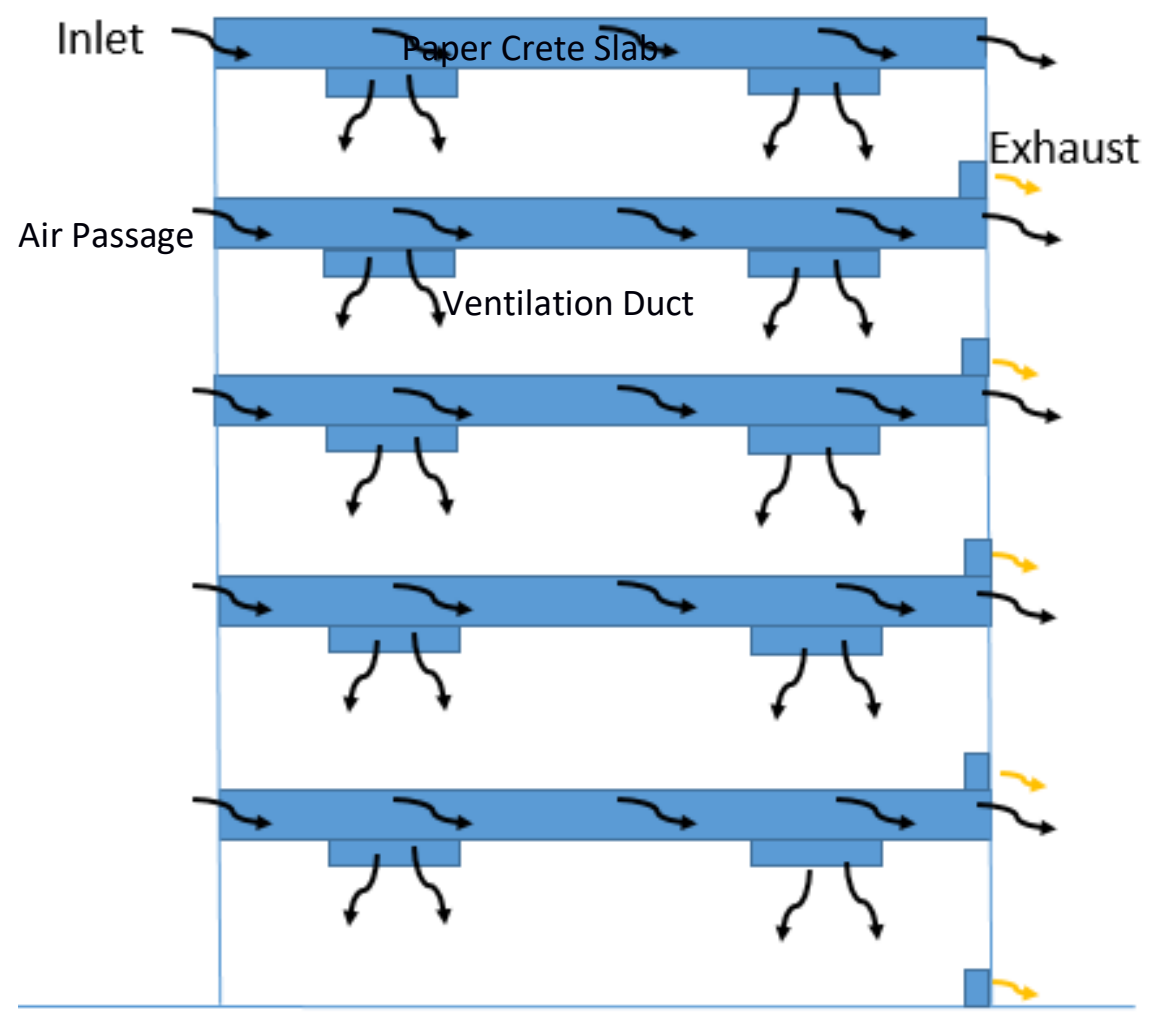

Ground Surface

Figure 1: Shows circulation of Natural air in Building without any Mechanical equipment's

Problem identified:

The majority of the houses in India are covered houses, dirt tiles and more numbers in solid material. Individuals favor that kind of material for the reasons like, minimal effort and simple upkeep. In any case, those material won't give a solid domain to the inhabitants since the warm conductivity will be relatively high. As indicated by the climate examine, India is one of the nation which gets more measure of warmth during summer season which causes dry spell in numerous territories. Therefore causing catastrophic event by diminishing the ground water level.

\section{MATERIALS AND METHODS}

5.1 Materials and Preparation

\section{Papercrete Upperlayer}

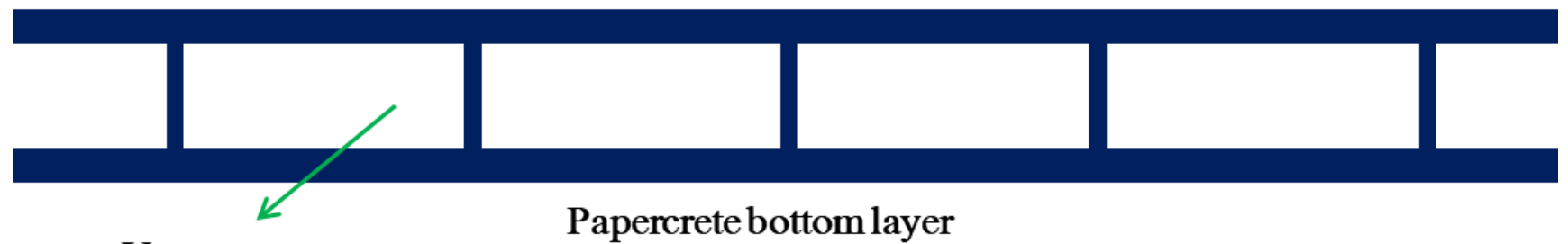

Vacuum

\section{Papercrete bottomlayer}


Figure 2: Proposed Papercrete Vacuum Roofing Unit

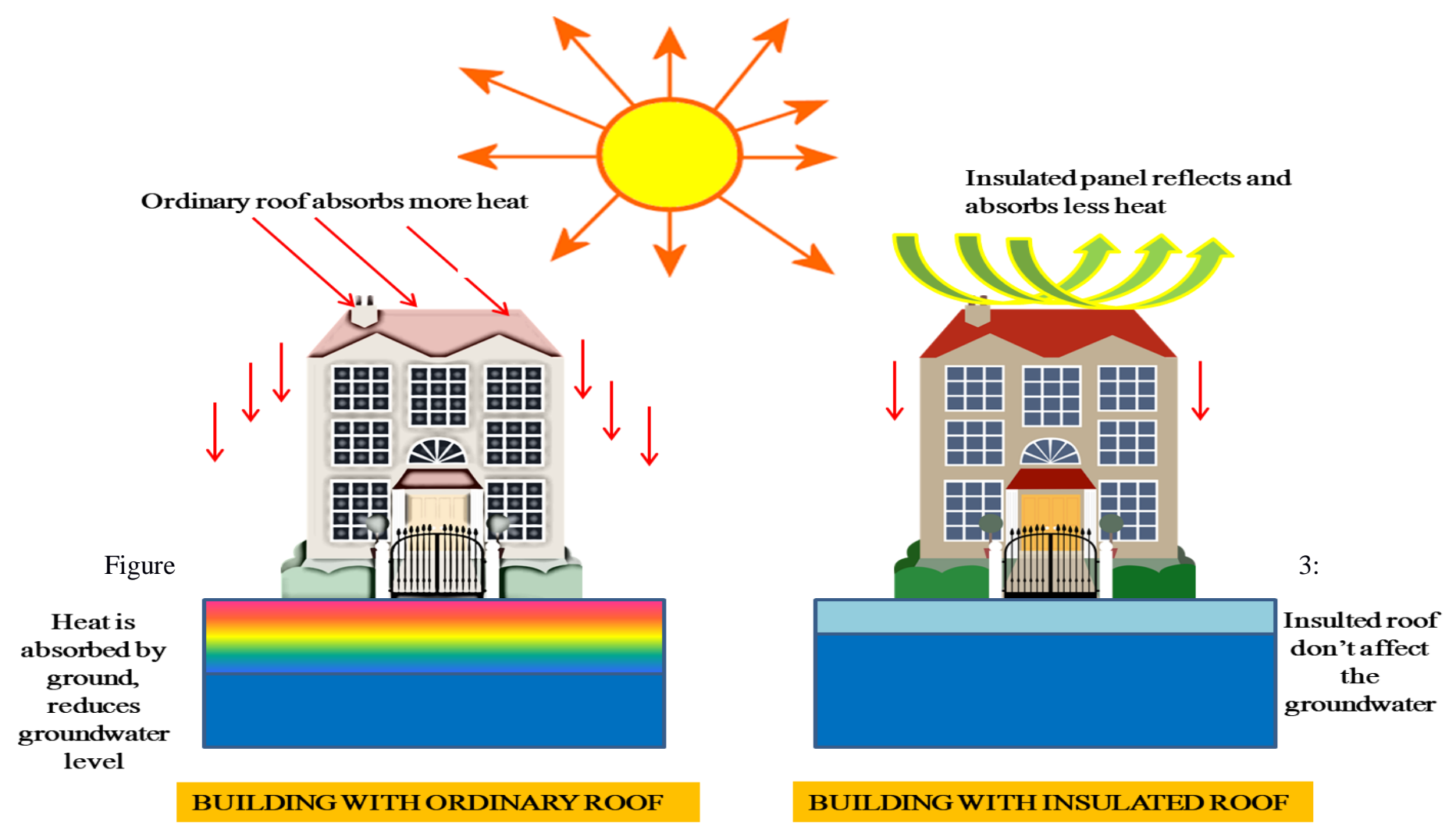

Ground Water Condition for Buildings with and without Insulated Roofing Unit

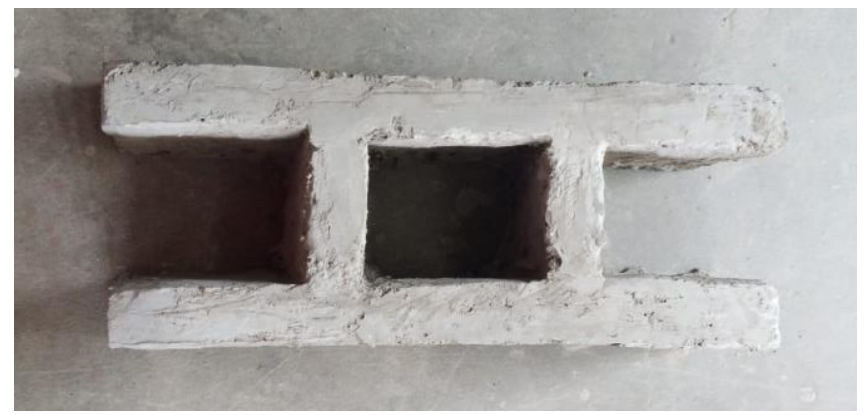

Figure 4: Cross section of paper Crete panel

Social pertinence and convenience of the task

- $\quad$ Maintaining the groundwater level is the need of great importance in our nation. By diminishing the structure heat, the profundity of warmth consumed by the ground from the structure will get decreased. This is encouraged by giving the protected rooftop units.

- Designing and testing of protected material units which is produced using reused paper squander with vacuum as filler will fill in as an ecoaccommodating material.

- It can be planned requiring little to no effort, since just the waste paper is utilized for the generation. So it is monetarily reasonable.

- Even low class individuals can manage the cost of it for their homes or any sorts of structures. 
- $\quad$ Since it gives characteristic cooling impact, outside cooling frameworks are maintained a strategic distance from which thus include the credit as green structure nature.

- $\quad$ For assembling reason, no imaginative innovation is received with the goal that no talented work is required for the generation perspective.

\section{RESULTS AND DISCUSSION}

To expand the elasticity of the unit, fibrocement is included alongside the paper Crete. It empowers us to make any tasteful shapes in material framework. Of every one of these focal points, the generation procedure doesn't includes any tremendous expense or gifted works. Numerous inquiries about demonstrates that customary protected materials, for example, stopper, fleece, and cellulose can save vitality to specific degrees. Be that as it may, the warmth in structures require the expanded protection without repaying the quality and with less expense. Subsequently by decreasing the structure warmth won't influence the ground water (Prasad, 2015)

A few looks into depended on gas filled boards whose gas directs less warmth than other. This undertaking goes in a similar channel, with a minor change in protection process. The vacuum doesn't lead heat, with this idea, the venture goes for building up the material framework by vacuum penetration in sandwich boards.

\subsection{Compressive Strength Test}

The accompanying table and diagram demonstrates the aftereffect of pressure test with different rates of Waste paper in cement. Paper Crete with $20 \%$ supplanting with coarse total shows higher Strength in examination with $10 \%$ and $30 \%$. The Strength of Paper Crete with $20 \%$ substitution shows results like that of ordinary cement.

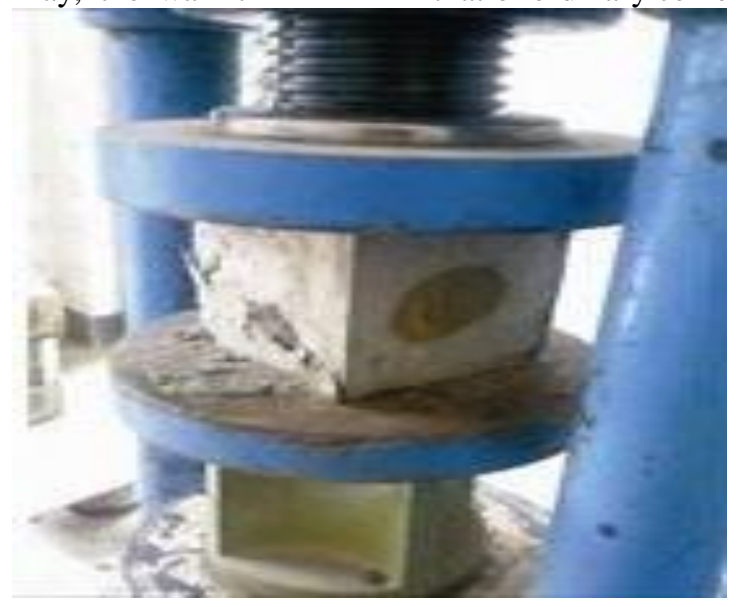

Figure 5: Compression test on concrete cube

Table 1: Shows the compressive strength of concrete with different percent of waste paper

\begin{tabular}{|l|l|l|l|}
\hline Conventional concrete & $10 \%$ replacement & $20 \%$ replacement & $30 \%$ replacement \\
\hline 7.6 & 7.1 & 7.4 & \\
\hline 13.1 & 12.8 & 13 & 7 \\
\hline 18.5 & 17 & 18.1 & 12 \\
\hline 19.6 & 18.2 & 19.3 & 15.7 \\
\hline
\end{tabular}




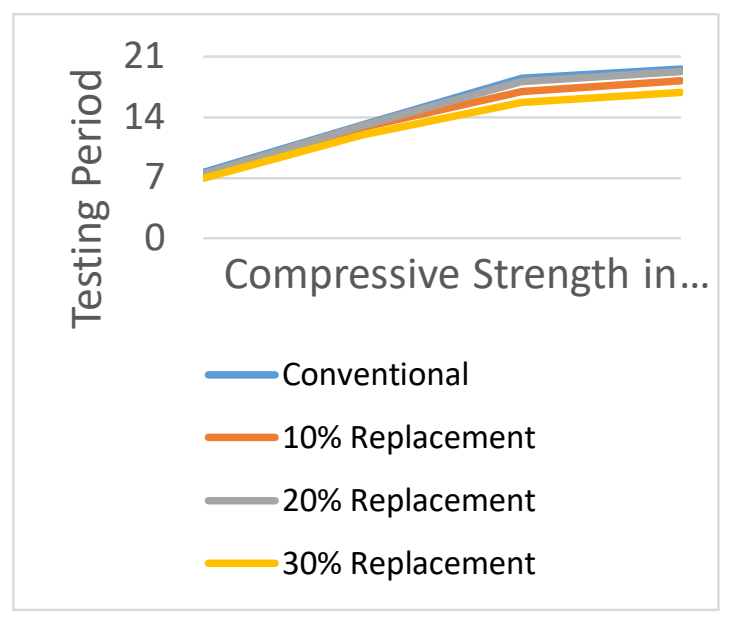

Figure 6: Graph shows Compressive strength Vs. Age of concrete

\section{CONCLUSION}

Paper Crete concrete with $20 \%$ substitution of Waste paper demonstrates higher quality when contrasted with $10 \%$ and $30 \%$ substitution. $20 \%$ substitution has the quality close to the show concrete. Most astounding quality when contrasted with straightforward material that will build purling dividing and cut down the expense of casing for establishment.

Production of paprecrete vacuum in separated rooftop section requires waste paper with Ferro bond.

Reusability of paper waste can be utilized for the equivalent. The creation procedure prompt voids accordingly diminishing the heap following up on the structure and empowering the structure as seismic safe. Reuse of material diminishes the strain on profitable assets, for example, fuel, woods and other related materials. From Testing it demonstrates a decent safe against acoustic just as warm Radiation. Cost of assembling can be decreased through incompetent work and waste materials (Garcia et al, 2008).

- Paper Crete cement is Light weight and incredibly simple to introduce.

- Esthetically wonderful

- Long life

- Sound protection due to sandwich PU froth protection

- Maintenance free

Acknowledgement

The Authors are thankful to Sri Krishna College of Technology for providing materials and Equipment's for Testing.

\section{REFERENCE}

[1] A. Hassani, H. Ganjidoust and A.A. Maghanaki, "Use of plastic waste (polyethylene terephthalate) in asphalt concrete mixture as aggregate replacement", Journal of Waste Management and Research, vol. 23, pp. 322-327, 2005.

[2] R. Srinivasan, K. Sathiya, and M. Palanisamy, "Experimental investigation in developing low cost concrete from paper industry waste", The Bulletin of the Polytechnic Institute of Jassy, Construction. Architecture Section (Romania), 2010.

[3] H. Yun, H. Jung and C. Choi, "Mechanical properties of paper Crete containing waste paper", 18th Int. Conf. on composite materials, 2011.

[4] M.S. Sugunya, "Lightweight bricks-made up of waste papers" International Journal of Computer \& Organization Trends, vol. 2(2), 2012.

[5] Singh, S., Nagar, R., Agrawal, V., Rana, A., \& Tiwari, A. "Sustainable utilization of granite cutting waste in high strength concrete", Journal of Cleaner Production, vol. 116, 223-235, 2016.

[6] C. Aciu, D.A. Ilutiu-Varvara, N. Cobirzan, and A. Balog, "Recycling of paper waste in the composition of plastering mortars", Procedia Technology 12, 295-300, 2014.

[7] R.Selvaraj, R. Priyanka, M. Amirthavarshini, Dr. S. Prabhavathy, "Evaluation of Paper Crete: An Innovative Building Material", International Journal of Engineering \& Advanced Research Technology, 1(6), 2015.

[8] S.Valls, A Yague and E.Vazquez, "Physical and mechanical properties of concrete with added dry sludge from a sewage treatment plant". Cement and Concrete Research, pp 2203-2208, 2004.

[9] Bashar.Mohammed and Ong Chuan Fang "Mechanical and durability properties of concretes containing paper-mill residuals and fly ash”, Construction and Building Materials, 2010.

[10] B.S. Mohammed, "Paper Crete as infill materials for composite wall system", European Journal of Scientific Research, 34(4), 455.

[11] Y.D. Shermale, and M.B. Varma, " Paper Crete: An Efficient Use of Waste Paper " Recent Trends in Civil Engineering and Technology, Vol. 5(3), pp 54-59, 2016.

[12] G.V.S. Prasad, "Study and Behaviour of some Properties of Paper Crete Brick with Modular Brick", International Journal of Engineering Research, 3(3), 2015. 
[13] I.B. Topcu, M. Canbaz, "Properties of concrete containing waste glass", Journal of Cement and Concrete Research, Vol. 34, pp 267-274, 2004.

[14] Isaac I. Akinwumi, M. Olasunkanmi, M. Olatunbosun, M. Oluwarotimi, Olofinnade, Paul O. Awoyera " Structural Evaluation Of Lightweight Concrete Produced Using Waste Newspaper And Office Paper " Civil And Environmental Research, Vol.6(7), pp 160-168, 2014.

[15] R.Garcia et al "Pozzolanic Properties of Paper Sludge Waste", Construction and Building Materials, Vol.22(7), pp 1484 - 1490, 2008. 